\title{
Avaliação ambiental do parque urbano Arnulplho Fioravante para adoção de estratégias de restauração
}

\author{
Environmental assessment of urban park Arnulpho Fioravanti for adoption of strategies for \\ restoration \\ MARIA LÍDA MATSUMOTO*, ZEFA VALDIVINA PEREIRA**, JOELSON PEREIRA GONÇALVES**, ANDRÉIA \\ SANGALLI**, SHALINE SÉFARA LOPES FERNANDES** \\ * Faculdade de Ciências Biológicas e Ambientais -FCBA, Universidade Federal da Grande \\ Dourados-UFGD, Dourados, MS. Email: mali.tsu@hotmail.com \\ ** Faculdade de Ciências Biológicas e Ambientais -FCBA, Universidade Federal da Grande \\ Dourados- UFGD, Dourados, MS
}

\begin{abstract}
Resumo
Este trabalho objetivou elaborar uma avaliação ambiental do Parque Arnulpho Fioravante, Dourados, MS, bem como propor uma estratégia de restauração para as APPs ali existentes. O parque localiza-se na área urbana da Cidade de Dourados entre as

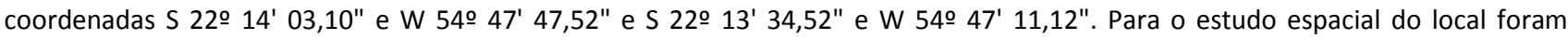
utilizadas técnicas de geoprocessamento e sensoriamento remoto. Para avaliar o grau de conservação das nascentes foi utilizado um protocolo de avaliação rápida de diversidade de habitats. Além disso, através de avaliação in loco, foi efetuado um inventário da flora e fauna existente. O Parque Arnulpho Fioravante encontra-se em péssimo estado de conservação. Suas nascentes encontramse todas impactadas, com grande acúmulo de lixo, deposição de esgoto e ausência de matas ciliares. Nas condições em que se encontra não atende as funções básicas que é de servir para a melhoria da qualidade de vida no ambiente urbano e da conservação da biodiversidade local. Nesse sentido, são necessárias medidas urgentes de revitalização e de um programa de gestão ambiental que garanta a manutenção da biodiversidade e ao mesmo tempo possa fornecer local adequado de lazer. Faz-se necessário também o desenvolvimento de ferramentas de sensibilização e transformação que promova mudanças de condutas na comunidade do entorno no sentido de possibilitar a percepção de problemas ambientais, fazendo com que cada pessoa assuma a sua responsabilidade perante o meio em que está inserida.
\end{abstract}

Palavras-chave: nascentes; gestão ambiental; parque urbano

\begin{abstract}
This study aimed to develop an environmental assessment Park Arnulpho Fioravante, Dourados, MS, and propose a restoration strategy for APPs found there. The park is located in the urban area of the City of Dourados between the coordinates S 22ㅇ 14' 03.10" W and 540 47' 47.52" S and 220 13' 34.52" W and 54 47' 11.12". For the study of spatial location techniques were used GIS and remote sensing. To assess the degree of conservation of the springs we used a protocol for rapid assessment of habitat diversity. Furthermore, through in-house evaluation was performed an inventory of existing flora and fauna. Arnulpho Fioravante Park is in disrepair. Its sources are all impacted, with greater accumulation of garbage, sewage disposal and lack of riparian forests. Under conditions in which he is does not meet the basic functions which is used to improve the quality of life in urban environment and local biodiversity conservation. Accordingly, urgent action is needed to revitalize and an environmental management program that ensures the maintenance of biodiversity and at the same time can provide a suitable place for leisure. It is necessary also to develop tools to raise awareness and change behaviors to promote changes in the surrounding community in order to allow the perception of environmental problems, so that each person assumes responsibility towards the environment in which it operates.
\end{abstract}

Key-words: sources; environmental management; urban park

\section{Introdução}

O processo acelerado da expansão urbana nos estados brasileiros tem proporcionado especulação imobiliária e crescimento urbano, sem o devido gerenciamento e sem políticas consistentes de planejamento e de ocupação do solo, proporcionando uma configuração de padrão de cidade em que o meio ambiente é severamente alterado. Assim, áreas legalmente protegidas, como Áreas de Preservação Permanentes, são ocupadas pela população, 
acarretando o comprometimento dos recursos ambientais, com prejuízo para a sociedade como um todo, especialmente aos que são obrigados a conviver dia a dia em situação precária (Guerra \& Cunha 2001, Brasil 2004).

Não ocorreu diferente em Dourados-MS, onde o processo de urbanização foi marcado pela utilização crescente e predatória dos seus recursos naturais. Um processo cumulativo que resultou numa paisagem extremamente alterada considerando sua condição original.

Essa ocupação desordenada ocasionou uma cadeia de impactos nos recursos hídricos provocando, assim, uma maior fragilidade e vulnerabilidade do ambiente. Atividades como desmatamentos, práticas agrícolas perniciosas, alteração da topografia, lançamento de resíduos industriais e domésticos, erosão e assoreamento, afetam a vida da população, trazendo diversos tipos de problemas, como as dificuldades na captação de água adequada para abastecimento, sua escassez, além da transmissão de doenças por veiculação hídrica entre outras (Rodrigues et al. 2009).

Essa modificação rápida e abrangente traz transtornos à natureza e, por conseqüência, afetam a qualidade da vida humana uma vez que está diretamente ligada ao acesso dos moradores à quantidade, qualidade e distribuição de espaços livres que possam permitir um saudável contato com a natureza, propiciando também possibilidades de socialização e expressão cultural (Richter \& Böcker 1998).

Neste sentido, a criação e manutenção de parques urbanos vêm ao encontro com os problemas levantados, pois as áreas verdes contribuem na obtenção de uma boa qualidade de vida no ambiente urbano adquirindo valor ecológico e humanístico, ampliando a representação do lugar da natureza na cidade (Guzzo 2006). Os parques urbanos funcionam como espaços privilegiados da cidade que além de servir para o lazer podem formar mosaicos ao longo do território, nos chamados Corredores Ecológicos, trazendo benefícios, não somente para a biodiversidade, mas também para a conservação do solo e dos recursos hídricos, além dos benefícios intangíveis como aqueles associados à contemplação da paisagem (Macedo \& Sakata 2003).

As áreas verdes urbanas exercem influência positiva para a regulação do microclima local, sobre o equilíbrio ecológico (principalmente como abrigo de espécies reguladoras de pragas urbanas e bioindicadoras), na qualidade do ar (por meio do sequestro de carbono e retenção de partículas sólidas emitidas por veículos), no abrigo à fauna (favorecendo o reconhecimento de novos habitats para a maior variedade de espécies animais) e na manutenção das propriedades de permeabilidade, fertilidade do solo, no amortecimento de ruídos (Feiber 2004).

A importância destas áreas verdes para a cidade é inegável, não só para os moradores ao redor das mesmas, mas também para toda a população, uma vez que ao mesmo tempo em que se conserva a vegetação nativa, possibilita a recreação e lazer da população urbana (Silva \& Ferreira 2006). Contudo, com o crescimento desordenado das cidades a maioria das áreas verdes que podem ser destinadas a parques encontram-se bastante alteradas.

Nessa situação encontra-se o Parque Arnulpho Fioravante, uma área que, embora tenha sido criada na década de 1980, como forma de garantir a conservação das nascentes do córrego Paragem, encontra-se bastante antropizada devido à ausência de cobertura vegetal, despejo de esgoto clandestino e disposição de lixo.

Assim, surge a necessidade de estratégias de recuperação e manejo dessa área para que, de fato, possa cumprir sua função de parque urbano que é de proporcionar o lazer à população, assim como de garantir a preservação da biodiversidade.

A este propósito, destaca-se a avaliação ambiental como fundamento do processo de recuperação a ser empregado. Tal procedimento, essencial para o conhecimento sobre a realidade dos impactos antrópicos, constitui a base para a geração do prognóstico ambiental e viabilizando a integração das análises ambientais, políticas e econômicas que compõem um plano de gerenciamento e manejo do Parque.

Nesse sentido, este trabalho objetivou elaborar um diagnóstico ambiental do Parque Arnulpho Fioravante, Dourados - MS, bem como propor uma estratégia de restauração para as Áreas de Preservação Permanente (APP) existentes no local.

\section{Metodologia}

\section{1. Área de estudo}

O parque Arnulpho Fioravante dispõe de uma área de 73 ha, estando localizado na região central da cidade de Dourados, entre as coordenadas S 22ㅇ 14' 03,10" e W 54응 47' 47,52" e S 22ㅇ 13' 34,52" e W 54ㅇ 47' 11,12" (Figura 1).

O Município de Dourados pertence à bacia hidrográfica do Rio Paraná e à sub-bacia do Rio Dourados. Sua área urbana é drenada por nove córregos, a saber: Laranja Doce, Água Boa, Rego-d'água, Paragem, Curral de Arame, Chico Viegas, Engano, Laranja Hay e Jaguapiru, todos encontrando-se em péssimo estado de conservação, com ligações clandestinas de esgoto, pelas quais recebem, diariamente, grande carga de efluentes domésticos, resíduos de óleo combustível e lixo (Luciano 2008). O córrego Paragem tem suas nascentes no Parque Arnulpho Fioravante, o que reforça ainda mais a necessidade de ações que visem a conservação do local.

O clima da região é considerado de transição entre o tropical e o subtropical e segundo a classificação de Köppen é do tipo Aw úmido com inverno seco, verão chuvoso, onde a temperatura média do mês mais frio é inferior a 18 으 $\mathrm{e}$ a do mês mais quente superior a $22^{\circ} \mathrm{C}$. A temperatura média anual varia de 20 a $22^{\circ} \mathrm{C}$, com as médias dos meses mais frio e mais quente oscilando, respectivamente, de 15 a $19 \circ \mathrm{C}$ e de 23 a 26 으 (Oliveira et al. 2000). 


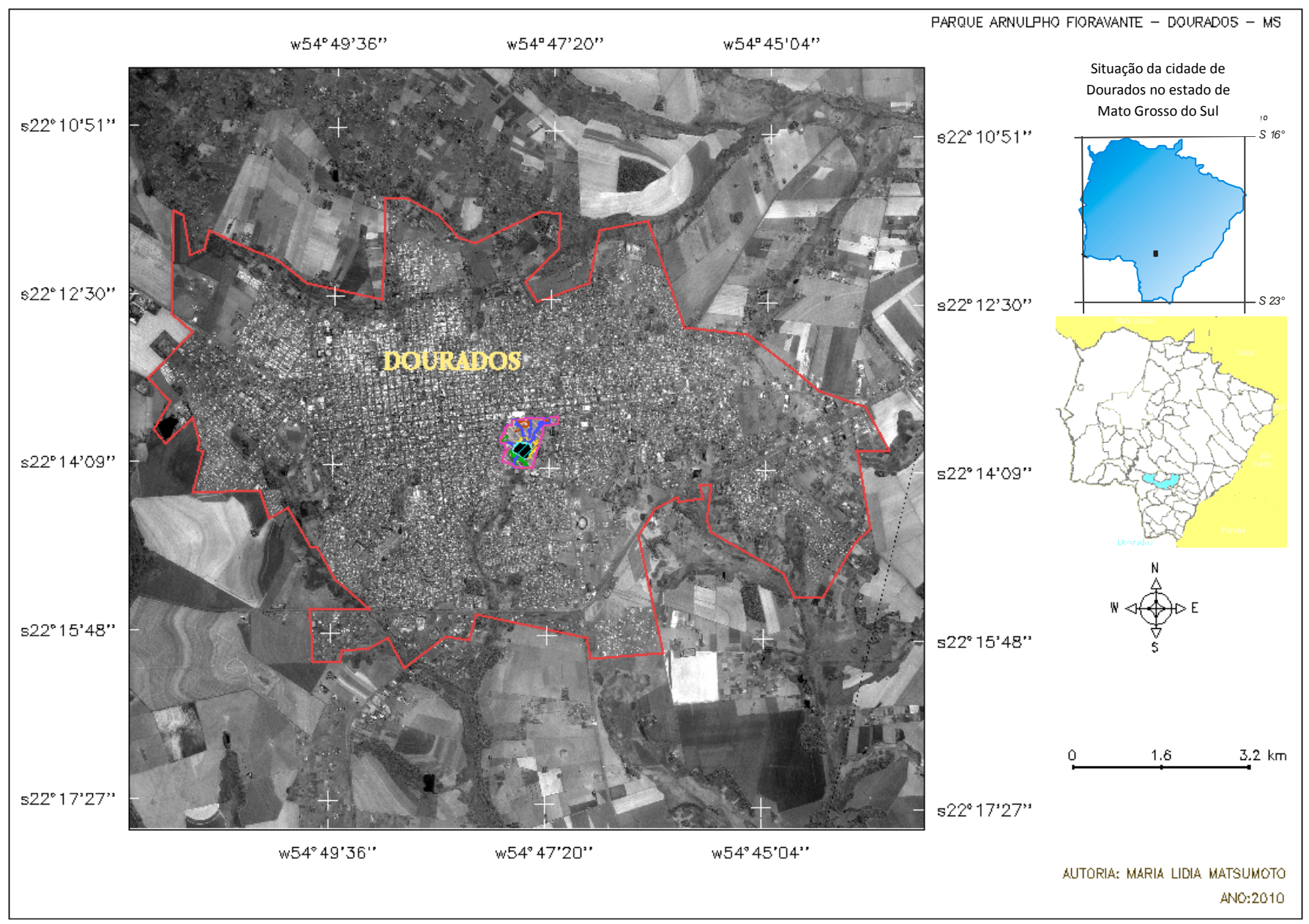

Figura 1 - Localização do parque Arnulpho Fioravante na cidade de Dourados, Mato Grosso do Sul.

A precipitação média anual varia de 1400 a $1700 \mathrm{~mm}$, sendo novembro, dezembro e janeiro o trimestre mais chuvoso; a distribuição anual das chuvas tem comportamento similar ao da temperatura, com os meses mais frios (junho, julho e agosto) apresentando também os menores índices de precipitação (Oliveira et al. 2000).

Predominam nesta região os solos avermelhados classificados como Latossolo Roxo e Latossolo Vermelho originados de rochas basálticas, é possível observar também Gleissolos que são solos minerais, hidromórficos e que estão localizados em baixadas, próximas às drenagens. Suas características são influenciadas pela contribuição de partículas provenientes dos solos das posições mais altas e da água de drenagem, uma vez que são formados em áreas de recepção de produtos transportados (Urchei 2001).

A vegetação original do Parque faz parte do domínio da Floresta Atlântica (IBGE 1992) e, de acordo com a classificação de Veloso et al. (1991), pode ser classificada como Floresta Estacional Semidecidual Ribeirinha. Contudo, a expansão da área urbana antes de sua criação, conferiu uma intensa descaracterização desta área.

\subsection{Diagnóstico ambiental}

Para o mapeamento e análise espacial da área foram utilizadas técnicas de geoprocessamento e sensoriamento remoto, através da interpretação visual de imagens CBERS obtidas pelo sensor HRC (High Resolution Camera), disposta em uma resolução espacial de $2,5 \mathrm{~m}$ e resolução espectral constituída por uma única banda pancromática que se distribui entre as regiões do visível e infravermelho próximo. O processamento da imagem, assim como a análise espacial da área foi realizado em Sistema de Informação Geográficas, com utilização do software Spring 5.0.1.

A modelagem das Áreas de Preservação Permanente apontadas no cenário foi feita mediante aplicação de operador espacial de vizinhança (função buffer) em representações vetoriais correspondentes à rede de drenagem local. Para tanto, admitiu-se, faixas de distâncias em conformidade com as larguras mínimas de APP preconizadas pelo Código Florestal Brasileiro (Lei oㅜ 4.770), quais sejam, 30 metros para cursos d'água de até dez metros de largura e 30 metros ao redor de lagos localizados em áreas urbanas consolidadas.

Depois de realizados os procedimentos no software Spring 5,0.1, para elaboração detalhada da carta imagem foi utilizado o módulo para geração de cartas denominado Scarta deste mesmo software, através do qual foi feita a inserção de grade de coordenadas geográficas norte geográfico, escala gráfica, legenda, dentre outros 
elementos cartográficos necessários a leitura das representações.

Para avaliar o grau de conservação das nascentes foi utilizado o protocolo de avaliação rápida de diversidade de habitats proposto por Callisto et al. (2002) e modificado para as condições locais. Este é composto por dois quadros, sendo que o primeiro visa à avaliação de trechos da bacia e nível de impactos ambientais decorrentes de atividades antrópicas, adaptado do protocolo proposto pela Agência de Proteção Ambiental de Ohio (EUA) (EPA, 1987). O segundo quadro foi adaptado do protocolo utilizado por Hannaford et al. (1997) e objetiva avaliar as condições de habitat e nível de conservação das paisagens naturais. 0 protocolo avalia um conjunto de parâmetros em categorias descritas e pontuadas. As pontuações finais refletem o nível de preservação das condições ecológicas dos trechos da bacia estudada, nas categorias: Naturais, Alterados e Impactados.

Além disso, através de avaliação in loco, foi efetuado um inventário da flora e fauna existente. Para a identificação da flora foram feitas coletas quinzenais no período de janeiro a maio de 2010. O material botânico foi coletado, herborizado mediante técnicas usuais e depositado no Herbário DDMS da Universidade Federal da Grande Dourados.

A identificação do material botânico foi realizada através da consulta de literaturas especializadas e especialistas, quando necessário. Para a apresentação das espécies, considerou-se a classificação da APG II conforme Souza \& Lorenzi (2005). A atualização taxonômica foi mediante consulta ao índice de espécies do Royal Botanic
Gardens - Kew (1993). A grafia dos autores seguiu a padronização recomentada por Brumitt \& Powell (1992).

Para a caracterizaçao faunística, foram realizadas entrevistas semi-estruturadas com funcionários do IMAM, Guarda Municipal e Policia Ambiental, observações diretas (visualização) e evidências indiretas como pegadas e tocas, também pela reunião e compilação de dados disponíveis, além de levantamento bibliográfico

\section{Resultados e discussão}

\subsection{Vegetação e Grau de Conservação das Nascentes}

Como é possível observar na Figura 2, dos quatro pequenos córregos cujas nascentes se encontram na área do Parque e os quais se unem para formar o Córrego Paragem, três possuem cobertura vegetal em segmentos isolados e portanto, apenas 3,54(ha) do total da área. Ademais, esses fragmentos apresentam-se bastante alterados, com grande efeito de borda e com muitas espécies invasoras, como ocorre no canto esquerdo do fragmento florestal da área $B$, formado quase que exclusivamente por leucena (Leucaena leucocephala (Lam.) R. de Wit.), espécies exótica fortemente alelopática, o que tem impedido o estabelecimento de outras espécies nativas no local. No fragmento a maioria das espécies encontradas são frutíferas exóticas.

A falta de cobertura vegetal nas margens desses córregos e nascentes tem causado a formação de processos erosivos que contribuem para um grande acúmulo de sedimentos nesses canais de drenagem, o que pode a médio e longo prazo provocar um rebaixamento do nível do lençol freático.

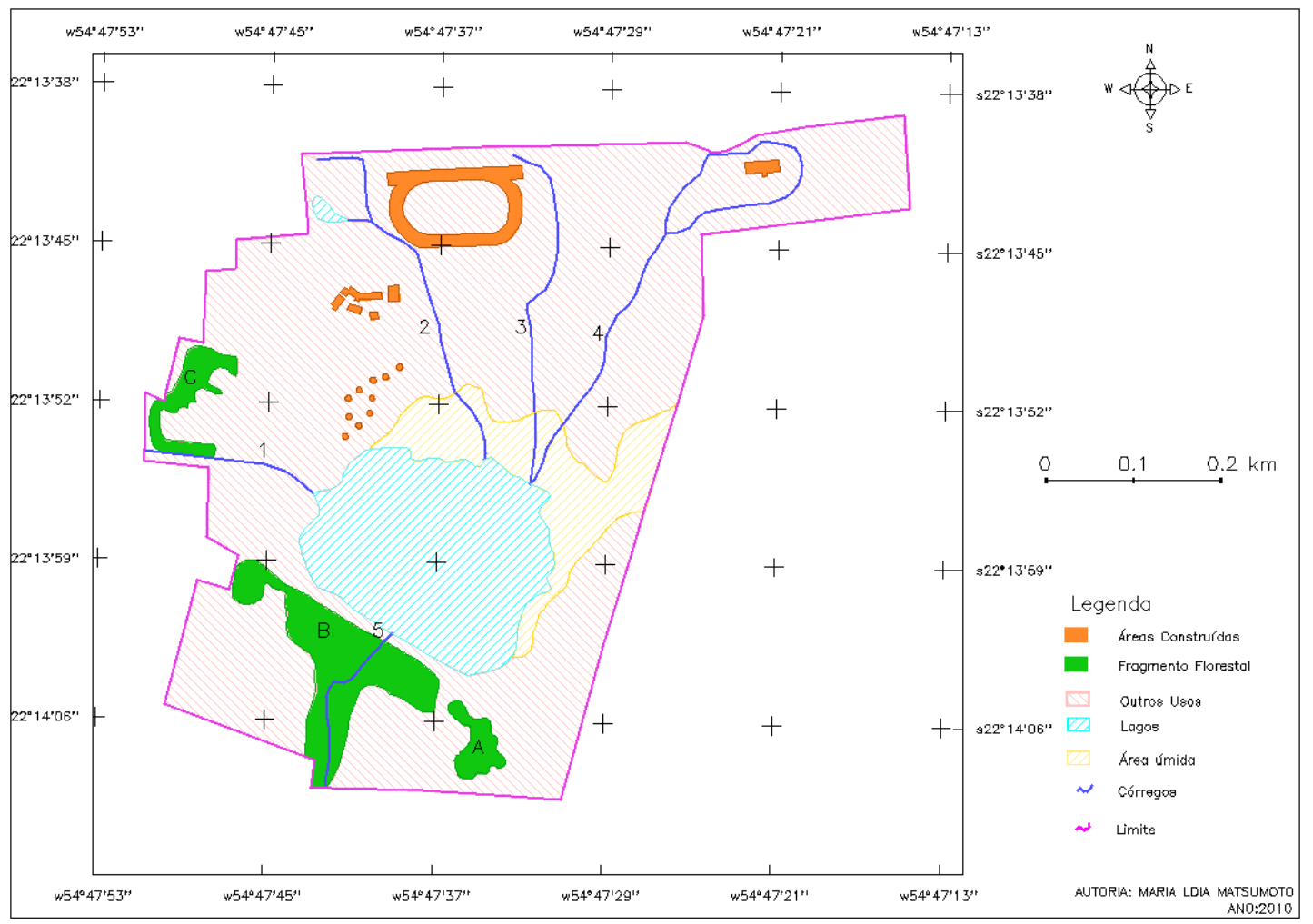

Figura 2 - Cenário atual do parque Arnulpho Fioravante no município de Dourados, MS. UFGD, 2010. 
Como já sugerido por Martins (2007) a função das matas ciliares em relação aos recursos hídricos está ligada a sua influência sobre uma série de fatores importantes, tais como: escoamento das águas da chuva, diminuição do pico dos períodos de cheia, estabilidade das margens e barrancos de cursos d'água, equilíbrio da temperatura das águas (favorece os peixes), ciclo de nutrientes existentes na água, entre outros. Assim, os solos sem cobertura florestal reduzem drasticamente sua capacidade de retenção de água de chuva, ou seja, em vez de infiltrar no solo, ela escoa sobre a superfície formando enormes enxurradas que não permitem o bom abastecimento do lençol freático, promovendo a diminuição da água armazenada. Com isso, reduzem-se as nascentes. As conseqüências do rebaixamento do lençol freático não se limitam às nascentes, mas se estendem aos córregos, rios e riachos abastecidos por ela. As enxurradas, por sua vez carregam partículas do solo iniciando o processo de erosão. Se não controladas, evoluem facilmente para as voçorocas.

A ausência de vegetação arbórea e a predominância de gramíneas encontradas nas margens das nascentes e córregos caracterizam-se como um fator de degradação, já que aumentam a probabilidade de erosões e potencializam o desmoronamento das margens, entre outros fatores agravantes. No âmbito da legislação ambiental, esta situação expõe a inconformidade da área em relação às determinações preconizadas pelo Código Florestal Brasileiro, as quais prevêem a manutenção de uma faixa mínima de 30 metros de área de preservação permanente para os cursos d'água de menos de 10 metros de largura e 50 metros para nascentes e áreas úmidas com solos hidromórficos (Brasil 1989).

Os resultados obtidos através da aplicação do protocolo de avaliação rápida da diversidade de habitats, também indicaram uma situação de impacto nas quatro nascentes existentes na área. Dentro dos parâmetros avaliados (ocupação, presença de ação antrópica, compactação do solo, assoreamento, deposição de sedimentos entre outros) obteve-se um somatório inferior a 40 pontos em todas as nascentes, sendo que as piores condições foram observadas na nascente um.

Tucci (2002) aponta que a concentração urbana desordenada e descontrolada, gera vários conflitos e problemas como a degradação ambiental dos mananciais, aumento do risco de contaminação das áreas de abastecimento pela poluição orgânica e química, emissão de efluentes doméstico e industrial nos rios. Os alagamentos motivados pela ocupação sem critérios do solo urbano e pelo gerenciamento inadequado de sua drenagem, assim como as conseqüências relacionadas à deficiências na coleta e disposição do lixo completam o conjunto dos principais desafios à gestão ambiental da cidade.

A preservação e manutenção da qualidade dos recursos hídricos constituem um grande desafio para a sociedade brasileira, especialmente para os órgãos responsáveis pelas tomadas de decisão, uma vez que a causa principal destes problemas geralmente se encontra nos aspectos institucionais relacionados com o gerenciamento dos sistemas fluviais e do meio ambiente urbano (Rodrigues et al. 2008).

\subsection{Biodiversidade}

Com relação à flora, embora a Tabela 1 evidencie uma diversidade razoável de espécies arbóreas, a maioria destas são consideradas espécies de estágios iniciais de sucessão e de ampla distribuição, demonstrando que a área já havia sofrido forte ação antrópica antes mesmo da criação do Parque. Contudo, essas espécies são essenciais para a manutenção da fauna local, além de servirem como fonte de propágulo para iniciar um processo de regeneração.

Verificou-se nas áreas encharcadas e na lagoa uma presença significativa de aguapé (Eichhornia azurea (Sw.) Kunth) e taboa (Typha domingensis Pers.). Essas espécies são consideradas depuradoras de águas poluídas, pois fazem a absorção de metais pesados. Desse modo é possível inferir que a água da lagoa está poluída.

Também foi possível constatar uma grande quantidade de espécies exóticas (Cinamomo, Manga, Flamboyant, Jamelão dentre outros) existentes na área (Tabela 1). Isto se justifica pelo fato de que até 2004 ainda existirem sitiantes residindo no local.

A vegetação é um dos componentes mais importantes à garantia na manutenção dos animais de um determinado ecossistema. Logo, as mudanças na estrutura e composição da componente vegetacional interferem diretamente na organização populacional da fauna. A simples alteração na altura da floresta é capaz de proporcionar uma redução na quantidade de nichos que abrigam uma diversidade de habitantes nos diferentes níveis da estratificação (horizontal e vertical), o que pode tornar o ambiente natural remanescente pequeno demais para abrigar espécies que necessitam de grandes áreas para sua sobrevivência (Dário 1999).

Como a área do Parque encontra-se muito alterada, observa-se um número reduzido de espécies da fauna (Tabela 2). Nota-se que a maioria dos representantes são do grupo das aves.

As aves frugívoras são importantes componentes na sucessão natural das fisionomias vegetais presentes em ambientes tropicais. Geralmente, em uma comunidade florestal, a dispersão da maioria das espécies arbustivas e arbóreas ocorre por zoocoria (Liebsch, 2007). Dentre os animais, as aves são responsáveis pela movimentação de propágulos de boa parte de muitas plantas que realmente interessam para a conservação de habitats (GalindoGonzález et al. 2000).

Observou-se no Parque uma grande quantidade de capivaras (Hydrochoerus hydrochoeris) e esse grande número tem preocupado alguns funcionários da defesa Civil, os quais alegam que, a deficiência no isolamento da área oferece risco iminente de acidentes, pela possibilidade de fuga desses animais em direção à movimentada avenida localizada à sua frente. 
Tabela 1 - Lista dos representante da flora amostradas no parque Arnulpho Fioravante, Dourados, MS, 2010.

\begin{tabular}{|c|c|c|c|}
\hline Nome popular & Espécie & Família & Hábito \\
\hline Açoita-cavalo & Luehea divaricata Mart. & Malvaceae & Arbóreo \\
\hline Alecrim-de-vassoura & Baccharis dracunculifolia DC. & Asteraceae & Arbustivo \\
\hline Almecega & Protium heptaphyllum (Aubl.) Marchand & Burseraceae & Arbóreo \\
\hline Amendoim - bravo & Pterogyne nitens Tul. & Fabaceae & Arbóreo \\
\hline $\begin{array}{l}\text { Aroeira } \\
\text { Aroeira-branca }\end{array}$ & $\begin{array}{l}\text { Myracrodruon urundeuva Allemão } \\
\text { Lithraea molleoides (Vell.) Engler }\end{array}$ & $\begin{array}{l}\text { Anacardiaceae } \\
\text { Anacardiaceae }\end{array}$ & $\begin{array}{l}\text { Arbóreo } \\
\text { Arbóreo }\end{array}$ \\
\hline Aroeira-mansa & Schinus terebenthifolius Raddi & Anacardiaceae & Arbóreo \\
\hline Assa-peixe & Vernonia ferruginea Less. & Asteraceae & Arbustivo \\
\hline Batata-de-purga & Ipomoea sp. & Convolvulaceae & Liana \\
\hline Brachiaria & Brachiaria SP & Poaceae & Herbácea \\
\hline Caju & Anacardium occidentale L. & Annacardiaceae & Arbóreo \\
\hline Cancum & Allophylus edulis (A.St.-Hil.) Radlk & Sapindaceae & Arbóreo \\
\hline Candeia & Gochnatia polymorpha (Less.) Cabrera & Asteraceae & Arbóreo \\
\hline Candiúva & Trema micrantha (L.) Blume & Cannabaceae & Arbóreo \\
\hline Canela & Nectandra megapotamica (Spreng.) Mez & Lauraceae & Arbóreo \\
\hline Capixingui & Croton floribundus Sprengel & Euphorbiaceae & Arbóreo \\
\hline Capororoca & Rapanea guianensis Aubl. & Myrcinaecae & Arbóreo \\
\hline Caraguatá & Bromelia balansae Mez & Bromeliaceae & Herbáceo \\
\hline Carapiá & Dorstenia brasiliensis Lam. & Moraceae & Herbáceo \\
\hline Cedro & Cedrela fissilis Vell. & Meliaceae & Arbóreo \\
\hline Chicha & Sterculia chicha A. St.-Hil. ex Turpin & Malvaceae & Arbóreo \\
\hline Chico-magro & Guazuma ulmifolia Lam. & Malvaceae & Arbóreo \\
\hline Cinamomo & Melia azedarach L. & Meliaceae & Arbóreo \\
\hline Cinco-folhas & $\begin{array}{l}\text { Schefflera morototoni (Aubl.) Maguire, } \\
\text { Steyerm. \& Frodin }\end{array}$ & Araliaceae & Arbóreo \\
\hline Copaíba & Copaifera langsdorffii Desf. & Fabaceae & Arbóreo \\
\hline Cruz de malta & Ludwigia SP & Onagraceae & Herbácea \\
\hline Erva-de-lagarto & Casearia sylvestris Sw. & Salicaceae & Arbóreo \\
\hline Farinha seca & Albizia hassleri (Chodat) Burkart & Fabaceae & Arbóreo \\
\hline Figueira & Ficus $s p$ & Moraceae & Arbóreo \\
\hline Flamboyant & Delonix regia (Bojer ex Hook.) Raf. & Fabaceae & Arbóreo \\
\hline Fumo bravo & Solanum mauritianum Scop. & Solanaceae & Arbustivo \\
\hline Ginseng brasileiro & Pfaffia glomerata (Spreng.) Pedersen & Amaranthaceae & Herbácea \\
\hline Goiaba & Psidium guajava $\mathrm{L}$. & Myrtaceae & Arbóreo \\
\hline Guanandi & Calophyllum brasiliensis Cambess. & Clusiaceae & Arbóreo \\
\hline Guapuruvú & Schizolobium parahyba (Vell.) S.F. Blake & Fabaceae & Arbóreo \\
\hline Guatambu & Aspidosperma parvifolium A. D.C. & Apocynaceae & Arbóreo \\
\hline Ingá & Inga vera Willd. & Fabaceae & Arbóreo \\
\hline Ipê-roxo & Tabebuia impetiginosa (Mart. ex DC.) Standl. & Bignoniaceae & Arbóreo \\
\hline Jacarandá - de -espinho & Machaerium aculeatum Raddi & Fabaceae & Arbóreo \\
\hline Jamelão & Syzygium cumini (L.) Skeels & Myrtaceae & Arbóreo \\
\hline Jaracatiá & Jacaratia spinosa (Aubl.) A. DC & Caricaceae & Arbóreo \\
\hline Jatobá & Hymenaea courbaril L. & Fabaceae & Arbóreo \\
\hline Jenipapo & Genipa americana L. & Rubiaceae & Arbóreo \\
\hline Jurubeba & Solanum paniculatum $\mathrm{L}$. & Solanaceae & Arbustivo \\
\hline Leitero & Peschiera fuchsiaefolia (A. DC.) Miers & Apocynaceae & Arbóreo \\
\hline Leitero & Sapium haematospermum Müll. Arg. & Euphorbiaceae & Arbóreo \\
\hline Leucena & Leucaena leucocephala (Lam.) de Wit & Fabaceae & Arbóreo \\
\hline Louro-pardo & Cordia trichotoma (Vell.) Arrab. Ex Steud. & Boraginaceae & Arbóreo \\
\hline Mamoeiro & Carica papaya $L$. & Caricaceae & Arbóreo \\
\hline Mamoneira & Ricinus communis $\mathrm{L}$. & Euphorbiaceae & Arbóreo \\
\hline
\end{tabular}




\begin{tabular}{|c|c|c|c|c|}
\hline Nome popular & Espécie & & Família & Hábito \\
\hline Mandacarú & Cereus giganteus Engelm. & & Cactaceae & Arbustivo \\
\hline Mangueira & Mangifera indica L. & & Anacardiaceae & Arbóreo \\
\hline Marinheiro & Guarea guidonia (L.) Sleumer & & Meliaceae & Arbóreo \\
\hline Mulungu & Erythrina mulungu Mart. ex Benth. & & Fabaceae & Arbóreo \\
\hline Paineira & Ceiba speciosa (A. St.-Hil.) Ravenna & & Malvaceae & Arbóreo \\
\hline Peito-de-pombo & Tapirira guianensis Aubl. & & Anacardiaceae & Arbóreo \\
\hline Picão-preto & Bidens pilosa $\mathrm{L}$. & & Asteraceae & Herbáceo \\
\hline Picão-vermelho & Bidens gardneri Baker & & Asteraceae & Herbáceo \\
\hline Pitanga & Eugenia uniflora L. & & Myrtaceae & Arbustivo \\
\hline Sangra-d'-água & Croton urucurana Baill. & & Euphorbiaceae & Arbóreo \\
\hline Sibipiruna & Caesalpinia peltophoroides Benth. & & Fabaceae & Arbóreo \\
\hline Tamarindo & Tamarindus indica $\mathrm{L}$. & & Fabaceae & Arbóreo \\
\hline Timbuva & $\begin{array}{l}\text { Enterolobium contortisiliquum } \\
\text { Morong }\end{array}$ & (Vell.) & Fabaceae & Arbóreo \\
\hline Urucum & Bixa orellana $\mathrm{L}$. & & Bixaceae & Arbóreo \\
\hline
\end{tabular}

Tabela 2 - Exemplares da fauna presentes no parque Arnulpho Fioravante, Dourados, MS, 2010.

\begin{tabular}{|c|c|c|}
\hline Nome popular & Família & Nome científico \\
\hline \multicolumn{3}{|c|}{ Peixes } \\
\hline Peixe muçum & Synbranchidae & Synbranchus marmoratus \\
\hline Peixe traíra & Erythrinidae & Hoplias malabaricus \\
\hline \multicolumn{3}{|c|}{ Anfíbios } \\
\hline Sapo cururu & Bufonidae & Bufo ictericus \\
\hline Sapo da floresta & Bufonidae & Bufo sp \\
\hline Perereca & Hylidae & Hyla sp \\
\hline Rã comum & Ranidae & Rana sp \\
\hline Rã comestível & $\begin{array}{c}\text { Leptodactylidae } \\
\text { Repteis }\end{array}$ & Leptodactylus labyrinthicus \\
\hline Cobra d'água & Colubridae & Helicops carinicauda \\
\hline Cobra falsa coral & Colubridae & Oxyrhopus \\
\hline Cobra verde & Colubridae & Liophis poecilogyrus \\
\hline Sucuri & Boidae & Eunectes sp \\
\hline \multicolumn{3}{|c|}{ Aves } \\
\hline Martin-Pescador-pequeno & Alcedinídeos & Chloceryle americana americana \\
\hline Martin-Pescador-grande & Alcedinídeos & Megaceryle torquata torquata \\
\hline Urubu Preto & Cartartídeos & Coragyps atratus foetens \\
\hline Pomba Juriti & Columbidae & Leptotila verreauxi sp \\
\hline Pomba Carijó & Columbidae & Columba picazuro \\
\hline Pomba saleira & Columbidae & Zenaida auriculata sp \\
\hline Coruja do campo & Estrigídeos & Speotyto cunicularia grallaria \\
\hline João de Barro & Furnarídeos & Furnarius rufus commersoni \\
\hline Andorinha-doméstica-grande & Hirundinídeos & Progne chalybea doméstica \\
\hline Pica-pau & Picidae & Colaptes c. campestres \\
\hline Beija-flor & Trochilidae & Colibri serrirostris \\
\hline Bem-te-ví & Tyrannidae & Pitangus sulphuratus \\
\hline \multicolumn{3}{|c|}{ Mamíferos } \\
\hline Preá & Caviidae & Cavia aperea \\
\hline Capivara & Hydrochaeridae & Hydrochoerus hydrochoeris \\
\hline Morcego das-frutas & Phyllostomidae & Artibeus lituratus \\
\hline
\end{tabular}

Cabe ressaltar, ainda, que essa espécie é hospedeira de várias doenças transmitidas ou adquiridas de animais domésticos, podendo representar algum perigo para as pessoas que frequentam o Parque. Assim, pesquisas devem ser conduzidas com o intuito de se fazer controle e manejo dessa população.

Alterações antrópicas sobre o ambiente natural da fauna implicam que os fragmentos remanescentes podem- se tornar pequeno demais para abrigar espécies que necessitam de grandes áreas para sobreviver. A fragmentação afeta principalmente as espécies raras e de baixa densidade populacional. Contudo, mesmo aquelas espécies que são generalistas e que apresentam alta densidade populacional também sofrem pressões com o adensamento urbano. 


\subsection{Condições fitossanitárias e de infra-estrutura}

Observou-se que a nascente do córrego 1 , constitui um escoadouro direto de esgoto, servindo de local para despejo de efluentes in natura provenientes de uma parte da cidade. Isto se deve, provavelmente, pela inexistência de rede coletora de esgoto nas áreas do entorno do Parque. Essa condição, além de ser desagradável para a população que faz uso do Parque, constitui um forte fator de degradação dos recursos hídricos e à fauna aquática. Quanto a isso, cabe mencionar que a eutrofização da lagoa existente no local, vem proporcionando a morte de um grande número de peixes, fato este confirmado pelo Instituto do Meio Ambiente Municipal (IMAM), responsável pelo monitoramento da área.

É importante ressaltar que a água doce, é um bem renovável desde que seja utilizada de forma adequada e cuidadosamente conservada, pois seu ciclo hidrológico global pode satisfazer as necessidades atuais e projetadas, de maneira sustentável. Por outro lado, as atividades humanas têm provocado, ao longo dos anos, intensos impactos nos ecossistemas aquáticos, os quais resultam em problemas relacionados à qualidade e fornecimento de água, que são de importância imediata e fundamental a toda humanidade (Corsan 2002).

Observa-se também por toda a região do parque uma grande quantidade de lixo, principalmente sacolas plástica e garrafas Pet, entulhos, pneus e roupas velhas. O fato de ter sido ocupado por sitiantes até o ano de 2004, aliado a outros fatores como a facilidade de acesso da comunidade do entorno, a falta de recipientes para a captação do lixo e da ausência de um trabalho de conscientização da população, são situações que contribuem para que o lixo constitua num dos mais significativos fatores de degradação do parque. Quando o lixo é acumulado próximo às nascentes, favorece ambientes de abrigo e procriação de inúmeros animais, sobretudo aos organismos veiculadores de doenças. Além de ser um potencial contaminador do solo que, por percolação ou escoamento superficial irá afetar a água. Dessa forma, os resíduos da decomposição do lixo, constituem uma importante ameaça à saúde da população através da água, propiciando a propagação de doenças por veiculação hídrica (FUNASA 2004).

O Parque também apresenta problemas de infraestrutura, como a ausência de sanitários para o uso público, falta de lixeiras, péssimas condições dos equipamentos de lazer como a pista de skate, arenas teatrais, deficiente sistema de iluminação e falta de manutenção da área de lazer como o campo de futebol e a pista de corrida, além do restrito quadro de funcionários - apenas um funcionário para a limpeza e outro para a vigilância - o que dificulta a manutenção, a conservação e a segurança no Parque.

\subsection{Proposta de restauração}

Os resultados obtidos pelo diagnóstico ambiental permitem o estabelecimento de planos estratégicos direcionados à recuperação das áreas de nascentes, os quais, focando características individualizadas de intervenção, permitem a seleção das melhores estratégias a serem empregadas em cada caso.

Quanto à presença de esgoto e lixo nos corpos de água, esses devem ser eliminados a partir da implantação de interceptores, coleta do lixo, instalação de lixeira, bem como garantir uma fiscalização efetiva para evitar futuras contaminações.

Em relação à contaminação decorrente de resíduos de óleo provenientes de postos de combustíveis e de garagens próximos ao local, deve haver uma fiscalização mais abrangente e rígida por parte do Ministério Público. Segundo o IMAM $80 \%$ das oficinas e postos de gasolina estão irregulares.

Para a recuperação da vegetação, será necessário o plantio total das espécies arbóreas nativas, uma vez que a área não apresenta regeneração natural. Na Figura 3, encontra-se a proposta de restauração da vegetação nativa.

Para atingir essa proposta, propõe-se a metodologia de Gandolfi \& Rodrigues (2007), adaptada para as condições da área de estudo. Será realizado o plantio de espécies de diferentes comportamentos (pioneiras, secundárias e/ou climácicas) e de diferentes grupos ecológicos, em linhas alternadas de plantio que representarão os módulos sucessionais. Essas linhas serão divididas em dois grupos funcionais, um de preenchimento e outro de diversidade.

As espécies do grupo de preenchimento têm como função o rápido recobrimento da área, criando um ambiente favorável ao desenvolvimento dos indivíduos do grupo de diversidade, e ao mesmo tempo desfavorecendo o desenvolvimento de espécies competidoras como gramíneas, lianas, etc., pelo sombreamento rápido da área de recuperação. As espécies pertencentes a esse grupo devem apresentar rápido crescimento e copa frondosa para recobrimento do solo. O florescimento precoce e a produção abundante de sementes em curto prazo também é um fator positivo, permitindo a atração de fauna e a constituição do banco de sementes que promoverá uma contínua regeneração natural (Gandolfi \& Rodrigues 2007).

Já o grupo de diversidade inclui todas as demais espécies da região, podendo ser de crescimento rápido ou lento, mas sempre com um grande número de espécies, ou seja, poucos indivíduos de um grande número de espécies, que é uma característica indispensável para a restauração da dinâmica florestal. Assim, nesta categoria, incluem-se espécies iniciais e finais da sucessão (secundárias iniciais, secundárias tardias e/ou clímax) que irão constituir a "floresta madura" e que, geralmente, dispõem de grande interação com a fauna. Estas espécies são criadoras de ambientes para a recolonização da área com outras formas de vida (epífitas, lianas, arbustos, etc.), abrigo e poleiro para animais, formação de sub-bosque, etc (Gandolfi \& Rodrigues 2007).

Assim, os grupos de plantio representam blocos de linhas alternadas, sendo uma linha de preenchimento (aproximadamente 20 espécies) e outra de diversidade 


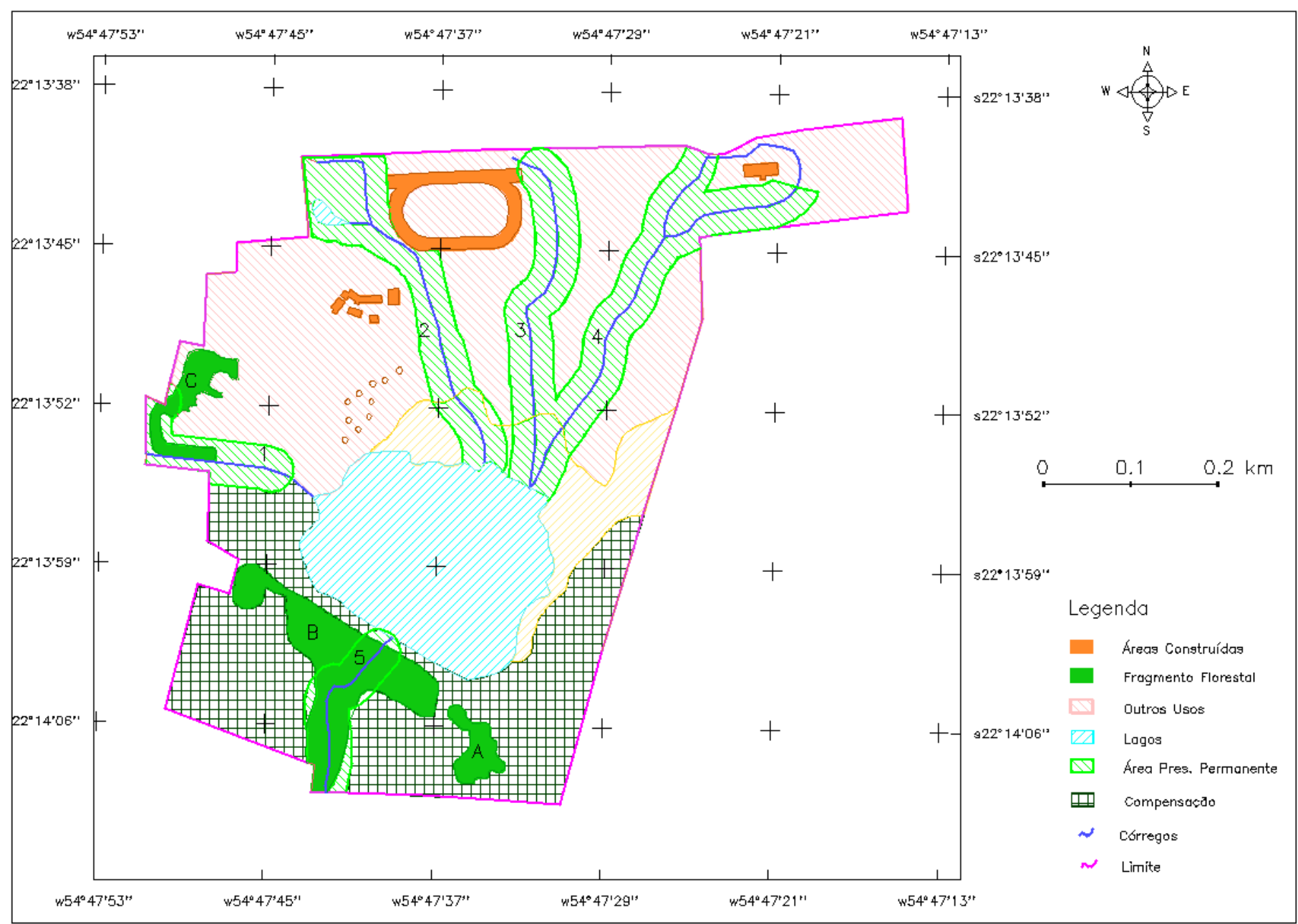

Figura 3 - Cenário possível após recuperação do parque Arnupho Fioravante, Dourados, MS. UFGD, 2010.

(aproximadamente 80 espécies). O espaçamento utilizado será de 3 metros entre linhas e 2 metros entre plantas.

E para que ocorra a interação das pessoas com a natureza, propõe-se a implantação de trilhas interpretativas com identificação de espécies florestais de destaque, permitindo assim, a elaboração de material educativo (folders, etc) além de promover o desenvolvimento de atividades de Educação Ambiental que contribuam para a manutenção desse e de outros Parques existentes no Município.

\section{Conclusões}

A partir do diagnóstico realizado observa-se que o Parque Arnulpho Fioravante encontra-se em péssimo estado de conservação. Suas nascentes encontram-se todas impactadas, com grande acúmulo de lixo, deposição de esgoto, espécies invasoras e ausência de matas ciliares. Nas condições em que se encontra a área não atende as funções básicas que é de servir para a melhoria da qualidade de vida no ambiente urbano e da conservação da biodiversidade local.

Dessa forma, faz-se necessário um plano emergencial de revitalização, através da recuperação da vegetação nativa das áreas ocupadas pelas espécies invasoras e consequentemente a recuperação gradativa das suas funções ecológicas; deve-se cessar o processo de eutrofização e de possível contaminação de todo o sistema hidrológico.

Além disso, há a necessidade de um programa de gestão ambiental que garantam a manutenção da biodiversidade e que, ao mesmo tempo, possa fornecer ao local uma condição adequada à prática do lazer e recreação, de modo a contribuir para a qualidade de vida à população.

Faz-se necessário, também, o desenvolvimento de ferramentas de sensibilização e transformação que promovam mudanças de conduta na comunidade do entorno, no sentido de possibilitar a percepção de problemas ambientais, fazendo com que cada pessoa assuma a sua responsabilidade perante o meio em que está inserida. 


\section{Referências bibliográficas}

BRASIL. 1989. Lei no 7.803 , de 18 de julho de 1989. Altera a redação da Lei no 4.771, de 15 de setembro de 1965. Disponível em: http://www.planalto.gov.br/ccivil_03/Leis/L7803.html>. Acesso em 25 maio 2010.

BRASIL. 2004. Ministério das Cidades. Política nacional de desenvolvimento urbano. 92p. (Cadernos Cidades Desenvolvimento 1). Disponível em: http://www.cidades.gov.br. Acesso em 14 janeiro 2010.

BRUMMITT R.K., POWELL C E. 1992. Authors of plant names. Kew: The Royal Botanic Gardens, 732p.

CALLISTO M., FERREIRA W.R., MORENO P., GOULART M., PETRUCIO M. 2002. Aplicação de um protocolo de avaliação rápida da diversidade de habitats em atividade de ensino e pesquisa (MG-RJ). Acta Limnol. Bras.,14(1):91-98.

CORSON W.H. 2002. Manual global de ecologia. 4. ed. São Paulo: Editora Augustus, 413p.

DÁRIO F.R. 1999. Influência de corredor florestal entre fragmentos da Mata Atlântica utilizando-se a avifauna como indicador ecológico. Piracicaba, ESALQ (Dissertação - Mestrado em Ciências Florestais).

EPA (Environmental Protection Agency). 1987. Biological criteria for the protection of aquatic life. Division of water quality monitoring and assessment, Columbus v.1 -III, 120p. (Surface water section)

FEIBER S.D. 2004. Áreas verdes urbanas imagem e uso - o caso do passeio público de Curitiba-PR. R. RAE GA, Curitiba: Ed. UFPR, 8: 93-105.

FUNASA (Fundação Nacional de Saneamento). 2004. Manual de saneamento. Disponivel em:<http: funasa.gov.br/site/funasa/pub/pub00.html>. Acessado em 04 junho 2010.

GALINDO-GONZÁLEZ J.G., GUEVARA S., SOSA V.J. 2000. Bat- and bird-generated seed rains at isolated trees in pastures in a tropical rainforest. Conservation Biology, 14 (6):1693-1703.

GANDOLFI S., RODRIGUES R.R. 2007. Metodologias de restauração florestal. In: Fundação Cargill (Coord.) Manejo florestal e restauração de áreas degradadas. São Paulo, 109-143.

GUERRA A.J.T., CUNHA S.B. (org.). 2001. Impactos Ambientais Urbanos no Brasil. São Paulo, Bertrand Brasil.

GUZZO P. 2006. Áreas verdes urbanas. Disponível em: <http://www.educar.sc.usp.br/biologia/prociencias/areasverd es.html>. Acesso em 28 junho de 2010.

HANNAFORD M., BARBOUR M., RESH V.H. 1997. Training reduces observe variability in visual based assessment of stream habitat. J. North Am. Benthol, Soc., 16: 853-860.

IBGE. 1992. Manual técnico da vegetação brasileira. Rio de Janeiro: Série Manuais Técnicos em geociências, 92p.

LIEBSCH D. 2007. Síndromes de dispersão de diásporos de um fragmento de floresta ombrófila mista em tijucas do sul, PR. Rev. Acad., 5: 167- 175.

LUCIANO L.C. 2008. Ribeiro : arquitetura, urbanismo e meio ambiente : exercício de cidadania. Luís Carlos Luciano; ilustrações e mapas Luiz Carlos Ribeiro; revisão Guilherme Medau e Paulo Roberto Cimo Queiróz. - Dourados, MS : Edição do Autor, 259p.

MACEDO S.S., SAKATA F.G. 2003. Parques Urbanos no Brasil. 2a ed. EDUSP/ Imprensa Oficial do Estado de São Paulo: São Paulo.

MARTINS S.V. 2007. Recuperação de matas ciliares. 2a Ed. Revista e ampliada: Editora Aprenda Fácil, Viçosa - MG: CPT, 255p.
OLIVEIRA H.DE. URCHEI M.A., FIETZ C.R. 2000. Aspectos físicos e socioeconômicos da bacia hidrográfica do Rio Ivinhema. Dourados: Embrapa Agropecuária Oeste, 52p.

RICHTER M., BÖCKER R. 1998. Developing an urban landscape management concept through the integration of environmental quality goals and environmental information systems. In: BREUSTE J., FELDMANN H., UHLMANN O. (Orgs.) Urban Ecology. Berlim: Springer.

RODRIGUES A.S.L., MALAFAIA G., CASTRO P.T.A. 2008. Avaliação ambiental de trechos de rios na região de Ouro Preto - MG através de um protocolo de avaliação rápida. REA - Revista, 10(1): 74-83.

RODRIGUES I., RODRIGUES T.P.T., FARIAS M.S.S., ARAÚJO A.F. 2009. Diagnóstico dos impactos ambientais advindos de atividades antrópicas na margem do rio Sanhauá e Paraíba. Centro Científico Conhecer - enciclopédia biosfera, Goiânia, $5(8)$.

ROYAL BOTANIC GARDENS - KEW. 1993. Index Kewensis on compact disc- manual. Oxford University Press. 67p.

SILVA F.B., FERREIRA W.R. 2003. Parques Urbanos de Uberlândia: Estudo de caso no Parque municipal Victória Siqueirolli. In: II Simpósio Regional de Geografia "Perspectivas para o cerrado no século XXI" Universidade Federal de Uberlândia - Instituto de Geografia, 1-11.

SOUZA V.C., LORENZI H. 2005. Botânica Sistemática: Guia ilustrado para identificação das famílias de Angiospermas da flora brasileira, baseado em APGII. Nova Odessa, São Paulo: Instituto Plantarum, p.291.

TUCCI, C.E.M. 2002. Gerenciamento da drenagem urbana. Revista Brasileira de Recursos Hídricos, 7(1): 5-28.

URCHEI M.A. 2001. O potencial dos solos do Mato Grosso do Sul para a agricultura irrigada. In: URCHEI, M.A.; FIETZ, C.R. (Ed.). Princípios de agricultura irrigada: caracterização e potencialidades em Mato Grosso do Sul. Dourados: Embrapa Agropecuária Oeste, 77-99.

VELOSO H.P., RANGEL FILHO A.R., LIMA J.C.A. 1991. Classificação da vegetação brasileira, adaptada a um sistema universal. Rio de Janeiro, RJ. IBGE, p124.
Manuscrito ID 19400

Submetido em outubro de 2010 Aceito em maioode 2012 